\title{
Fabrication of Electrospun Polyamide-6/Chitosan Nanofibrous Membrane toward Anionic Dyes Removal
}

\author{
Mozhdeh Ghani, Ali Akbar Gharehaghaji, Mokhtar Arami, \\ Negar Takhtkuse, and Babak Rezaei \\ Textile Engineering Department, Amirkabir University of Technology, Tehran, Iran \\ Correspondence should be addressed to Ali Akbar Gharehaghaji; aghaji@aut.ac.ir
}

Received 28 May 2013; Revised 8 November 2013; Accepted 22 November 2013; Published 16 February 2014

Academic Editor: Carlos R. Cabrera

Copyright (c) 2014 Mozhdeh Ghani et al. This is an open access article distributed under the Creative Commons Attribution License, which permits unrestricted use, distribution, and reproduction in any medium, provided the original work is properly cited.

\begin{abstract}
Nanofibrous filter media of polyamide-6/chitosan were fabricated by electrospinning onto a satin fabric substrate and characterized by scanning electron microscopy (SEM), Fourier transform infrared spectroscopy (FTIR), and water contact angle (WCA). Anionic dye removal capability of the filter was investigated for Solophenyl Red 3BL and Polar Yellow GN, respectively, as acidic and direct dyes were investigated with respect to solution parameters ( $\mathrm{pH}$ and initial dye concentration) and membrane parameters (electrospinning time and chitosan ratio) through filtration system. Experiments were designed using response surface methodology (RSM) based on five-level central composite design (CCD) with four parameters to maximize removal efficiency of the filter media. Moreover, the effect of parameters and their likely interactions on dye removal were investigated by mathematically developed models. The optimum values for solution $\mathrm{pH}$, initial dye concentration, electrospinning time, and chitosan ratio were predicted to be $5,50 \mathrm{mg} / \mathrm{L}, 4 \mathrm{hr}, 30 \%$ and $5,100 \mathrm{mg} / \mathrm{L}, 4 \mathrm{hr}, 10 \%$, respectively, for achieving $96 \%$ and $95 \%$ removal of Solophenyl Red 3BL and Polar Yellow GN. Evaluation of the estimation capability of applied models revealed that the models have a good agreement with experimental values. This study demonstrated that polyamide-6/chitosan nanofibrous membrane has an enormous applicable potential in dye removal from aqueous solutions.
\end{abstract}

\section{Introduction}

Wastewater from textile industry is contaminated by various dyes, which are not biodegradable, carcinogenic and can be a contaminating for fresh water. In general, typical treatment methods are not efficient enough because of economical and technical reasons. Various techniques for the dye removal have been investigated [1], among which membrane media are a topic of great interest for effluent treatment. Since these systems do not require any addition of chemical agents $[2,3]$ and also has potential to recycle the effluent, this minimizes the consumption of chemicals in dyeing process and would save energy consumed by providing the ability of using hot effluent to heat fresh water [4].

Surface area and porosity of electrospun nanofibrous membranes (ENMs) make them more appropriate for the dye removal from wastewaters. The high surface area provides excessive adsorption sites for dye adsorption and the higher porosity leads to smaller driving forces to push the water through the membrane which make the process less energy intensive and facile [5].

There are many researches on the use of ENMs for water treatment. For example, the functional polyethersulfone (PES) nanofibrous membrane was particularly useful for water purification [6]. Electrospun PAN nanofibrous membrane exhibited high ability to remove particle separation applications especially from water [7]. Cyclodextrin-functionalized nanofibrous membranes exhibited high adsorption capacity for indigo carmine dye [8]. Also a micronanostructure poly (ether sulfones)/poly (ethyleneimine) nanofibrous membrane was utilized as an adsorbent for anionic dyes [9].

Using polysaccharide-based materials in a membrane process has received considerable attention, because of their particular structure, physicochemical characteristics, high reactivity [10], and biocompatibility and biodegradability properties [11]. As a natural polymer, chitosan essentially demonstrates amazing properties such as biocompatibility, biodegradability, antimicrobial activity, nontoxicity, and 
absorption capabilities [12]. It is extremely cost-effective due to accessibility of chitin in nature [13], and it has high contents of amino and hydroxyl functional groups. Owing to these properties, chitosan is widely used in removal of contamination from wastewater [14]. Recently, the polyamidee-6/chitosan blend nanofibers have been successfully produced by electrospinning [11, 15-17]. Polyamide- 6 as a biodegradable, biocompatible, and synthetic polymer has strong mechanical and physical properties [18]. It seems that electrospinning of polyamide-6/chitosan blends nanofibers and may combine the advantages of polyamide- 6 together with those of chitosan that has high hydrophilicity, biocompatibility, biodegradability, and antibacterial and antifungal activities. So, blending of these materials could be developed for membrane applications [17].

In this study, the nanofibrous membranes based on a series of polyamide-6/chitosan composite onto a satin fabric were fabricated. Using central composite design (CCD) and removal efficiency of two anionic (acidic and direct) dyes were investigated as a function of solution $\mathrm{pH}$, initial dye concentration, electrospinning time, and chitosan ratio. Systematic study of solution and nanofibrous membrane parameters has been reported for the first time in this paper.

\section{Experimental}

2.1. Materials. Polyamide-6 $\left(M_{w} \sim 25,000 \mathrm{~g} / \mathrm{mol}\right)$ was purchased from Iran Petrochem Institute. Chitosan $\left(M_{w} 338,000\right.$ with $86 \%$ deacetylation) was purchased from Hannes Nutripharm. Formic acid (FA) as a solvent (99/99\%) from Merck was used to dissolve the blends of chitosan and polyamide- 6 . Tween 20 was used as a nonionic surfactant, Polar Yellow GN was used as an Acid Yellow 117, and Solophenyl Red 3BL was used as a C.I. Direct Red 80, was supplied by Ciba. A satin fabric was used as a substrate of nanofibrous membrane. Distilled water was used throughout this work. All the materials were used as received.

2.2. Preparation of Electrospun Membranes. Polyamide-6 chips and chitosan powder at a concentration of $10 \mathrm{wt} \%$ were blended in formic acid solution (10\% wt/v) at room temperature using a laboratory magnetic stirrer for 6 hours to ensure complete dissolution of the solutes and obtaining homogeneous solution. In order to verify the ability of chitosan in removal of dyes, various ratios of polyamide$6 /$ chitosan $(100 / 0,90 / 10,80 / 20,70 / 30$, and 60/40) were utilized to prepare the blended nanofibrous membrane. Meanwhile, the nonionic surfactant was utilized in order to provide electrospinnability of the blended solution.

The solutions were loaded into a $5 \mathrm{~mL}$ plastic syringe equipped with a needle tip (22G, length $=34 \mathrm{~mm}$, outer diameter $=0.7 \mathrm{~mm}$, and inner diameter $=0.4 \mathrm{~mm}$ ). Electrospinning was performed using a high-voltage power supply which can generate DC voltage up to $40 \mathrm{kV}$. A grounded drum was rotated at a constant speed ( $20 \mathrm{rpm})$ by a DC motor to collect the nanofibers, which was kept at a distance of $10 \mathrm{~cm}$ from the needle tip. All experiments were conducted at room temperature. In the current study, electrospun nanofibers were collected on a satin fabric under the determined conditions. Assessment of filtration efficiency of the substrate showed that its efficiency was negligible.

2.3. Characterization of Membranes. Morphology and diameter of the polyamide-6/chitosan nanofibrous membrane were investigated by scanning electron microscopy (SEM, Philips XL-30) at an accelerating voltage of $20 \mathrm{kV}$. Samples were gold-coated before SEM. Average diameter and diameter distribution of 100 random fibers were measured from the SEM images using image J software (National Institute of Health, USA).

FT-IR spectroscopy was used to investigate the functional groups of polyamide-6/chitosan nanofibers membrane on a Nicolet Nexus670 instrument. The FTIR tests were carried out using chitosan powder, polyamide- 6 nanofiber, and polyamide-6/chitosan nanofibrous membrane (80/20 weight ratio).

The water contact angle (WCA) of the polyamide-6/chitosan electrospun nanofibrous membranes was measured using camera color video (model no. SSC-DC318P), PCTV Vision, and Image J software. This was after dispensing the droplet on the membrane and taking photo after 4 seconds. For each sample, the WCA was measured at five different spots and the values were computed by Image J software and averaged values were reported.

2.4. Experimental Design. CCD as a popular second order experimental design was used to design the experiment. It allows estimating the second degree polynomial equation for determination of the relationships between the independent variables and the responses and gives information about interaction between independent variables in their relation to the responses. This design requires an experiment number according to $N=2^{k}+2 k+C_{p}$, where $k$ is the number of factors and $C_{p}$ is the replicate number of the central point. In CCD, all factors are studied in five levels $(-\alpha,-1,0,+1,+\alpha)$, where $\alpha$ represents experimental points distance from center point $[19,20]$. The independent variables which are used in this study were coded according to following equation:

$$
x_{i}=\frac{X_{i}-X_{0}}{\Delta X},
$$

where $x_{i}$ is the dimensionless coded value of the $i$ th independent variable, $x_{i}$ is the uncoded value of the $i$ th test variable, $X_{0}$ is the value of $x_{i}$ at the center point, and $\Delta X$ is the step change value. The relationship of the independent variables in coded values and the response was calculated by

$$
\eta=\beta_{0}+\sum_{i=1}^{k} \beta_{i} X_{i}+\sum_{i=1}^{k} \beta_{i i} X_{i} X_{i}+\sum_{i=1}^{k-1} \sum_{j=i+1}^{k} \beta_{i j} X_{i} X_{j}
$$

where $\eta$ was the predicted response and $\beta_{0}, \beta_{i}, \beta_{i i}$, and $\beta_{i j}$ are constants of the linear coefficient, the squared coefficient, and the cross-product coefficient, respectively. In this equation $x_{i}, \ldots, x_{n}$ are the input variables and $k$ is the number of independent parameters [20].

Efficiency of dye removal from aqueous solution using electrospun nanofibrous membrane depends on many 


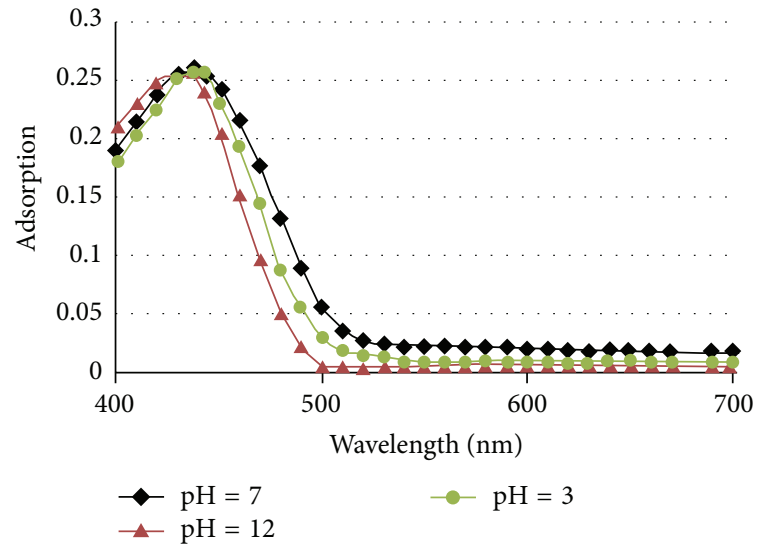

(a)

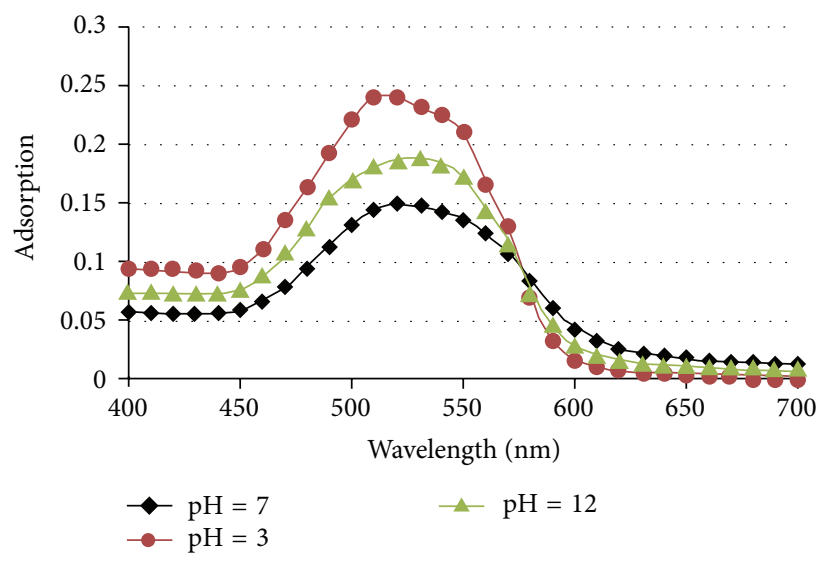

(b)

FIGURE 1: Effect of $\mathrm{pH}$ solution on the $\lambda_{\max }$ adsorption behavior for (a) Solophenyl Red 3BL and (b) Polar Yellow GN.

TABLE 1: Levels of different independent variables in coded and actual forms.

\begin{tabular}{lccccc}
\hline \multirow{2}{*}{ Independent variable } & \multicolumn{5}{c}{ Range and levels } \\
& $-\alpha(-2)$ & -1 & 0 & +1 & $+\alpha(+2)$ \\
\hline A: solution pH & 3 & 5 & 7 & 9 & 11 \\
B: initial dye concentration $(\mathrm{mg} / \mathrm{L})$ & 25 & 50 & 75 & 100 & 125 \\
C: electrospinning time (hr) & 1 & 2 & 3 & 4 & 5 \\
D: chitosan ratio (\%) & 0 & 10 & 20 & 30 & 40 \\
\hline
\end{tabular}

parameters which can be divided into three main categories: solution parameters (i.e., initial concentration, solution $\mathrm{PH}$, temperature of solution and, etc.), structural parameters of membrane (i.e., structural properties of polymer, thickness, porosity, nanofiber diameter, etc.), and processing parameters (i.e., pressure and flux, etc.). In order to identify the optimization conditions of dye removal, solution $\mathrm{pH}(\mathrm{A})$, initial dye concentration (B) as solution parameters, chitosan ratio in the blended solution $(\mathrm{C})$, and electrospinning time (D) as membrane parameters were considered. Each of the independent variables was studied at five different levels containing two star points and six replications of the central point with a total of 30 experiments. The range and levels of independent variables are given in Table 1.

In order to determine the range of solution $\mathrm{pH}, \lambda_{\max }$ was evaluated under various $\mathrm{pH}$ values ranging between 3 and 12 at constant concentration. As shown in Figure 1, the dye structures are stable over the applied $\mathrm{pH}$, because the $\lambda_{\max }$ has not changed significantly in comparison with neutral solution $(\mathrm{pH}=7)$.

2.5. Filtration Experiments on the Treatment of Dye Solution. A dead-end filtration cell (Figure 2) was used to characterize the filtration performance of the polyamide-6/chitosan membranes. The filtration apparatus was $50 \mathrm{~mL}$ membrane filtration cell with an effective area of $3.8 \mathrm{~cm}^{2}$. All tests were carried out at a constant pressure of 0.5 bar using a nitrogen storage cylinder at room temperature. Each solution was passed through the membrane three times consecutively and then the dye removal was evaluated. The concentrations of dye solutions were measured by a UV-vis spectrophotometer (Cary 100, Varian) at wavelength of $\left(\lambda_{\max }\right) 438$ and $521 \mathrm{~nm}$ for Polar Yellow GN and Solophenyl Red 3BL, respectively, and calibration experiments were carried out separately. The chemical formula, structure, molecular weight, and absorption wavelength of dyes are given in Table 2. Dye removal efficiency $(\% R)$ was calculated using the following equation:

$$
\% R=\frac{C_{0}-C}{C_{0}} \times 100 \%,
$$

where $C_{0}$ and $C$, are the primary and after treatment concentration, respectively.

\section{Results and Discussion}

3.1. Preparation and Characterization of the Polyamide-6/Chitosan Membrane. The SEM images of nanofibers with the corresponding histogram of the nanofiber diameter distribution are shown in Figure 3. As Figure 3(a) shows, under the experimental conditions, the polyamide-6/chitosan (100/0) nanofibers with average diameter of $54 \mathrm{~nm}$ and desirable morphology could be obtained. Since attempts to obtain nanofiber from the blended solutions were unsuccessful, small amount of Tween 20 as a nonionic surfactant was introduced in the solution. The nanofiber diameter tended to increase with increase of chitosan content in the blended solution which is due to increase in the viscosity of solution (Figures 3(b)-3(e)). As reported by Deitzel et al. [21] at very high viscosity values there is difficulty in the ejection of jets from polymer solution and it results in a larger fiber diameter. Moreover, the desirable morphology converted to defective structure with increasing the chitosan content in the blend solution. The experiments show that increasing of chitosan ratio above $40 \%$ lead to a rise in solution viscosity in which electrospinning became impossible.

Figure 4 shows the FTIR spectrum of chitosan, pure polyamide-6, and electrospun nanofibers of polyamide- $6 /$ chitosan at $80 / 20$. In spectrum (a), a broadband at $3,416 \mathrm{~cm}^{-1}$ due 
TABLE 2: Characteristics of dyes.

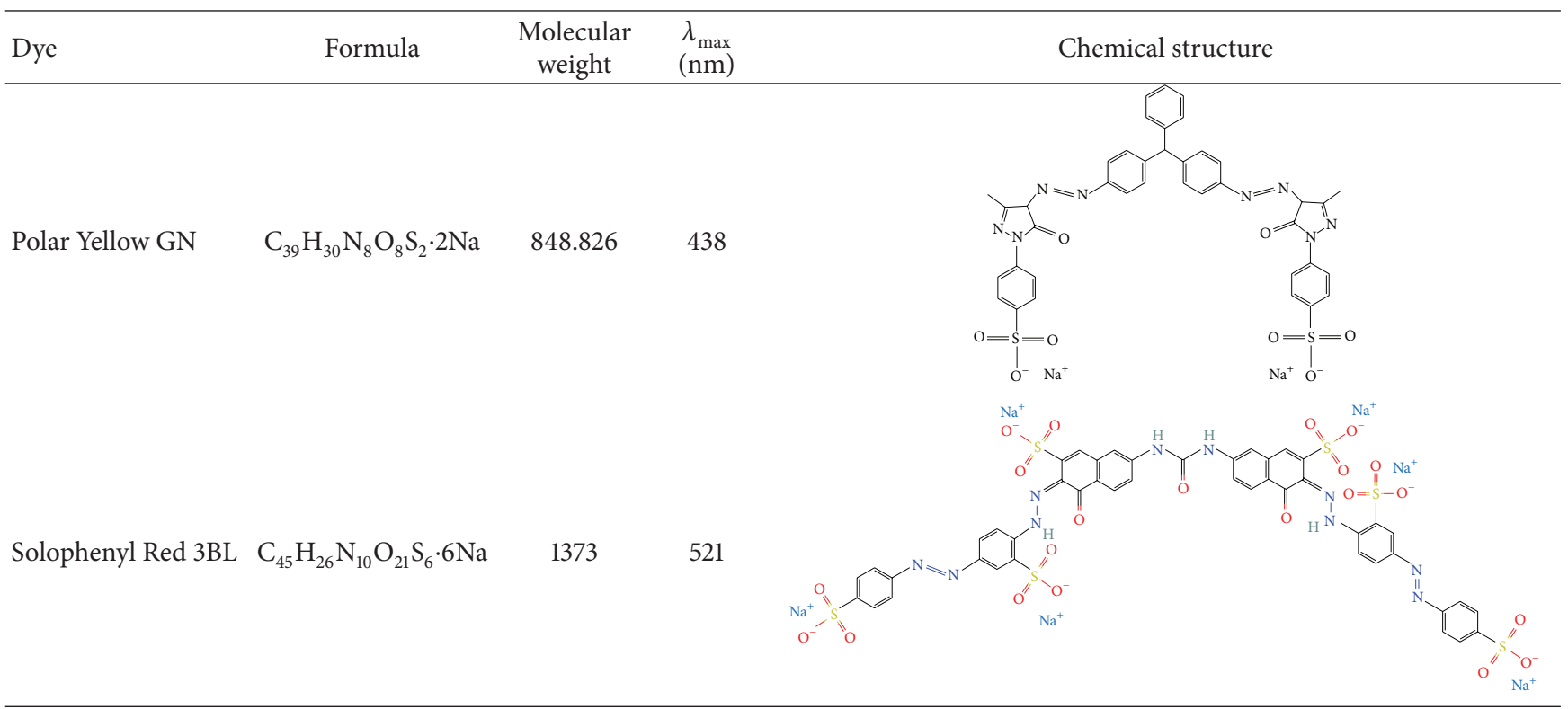

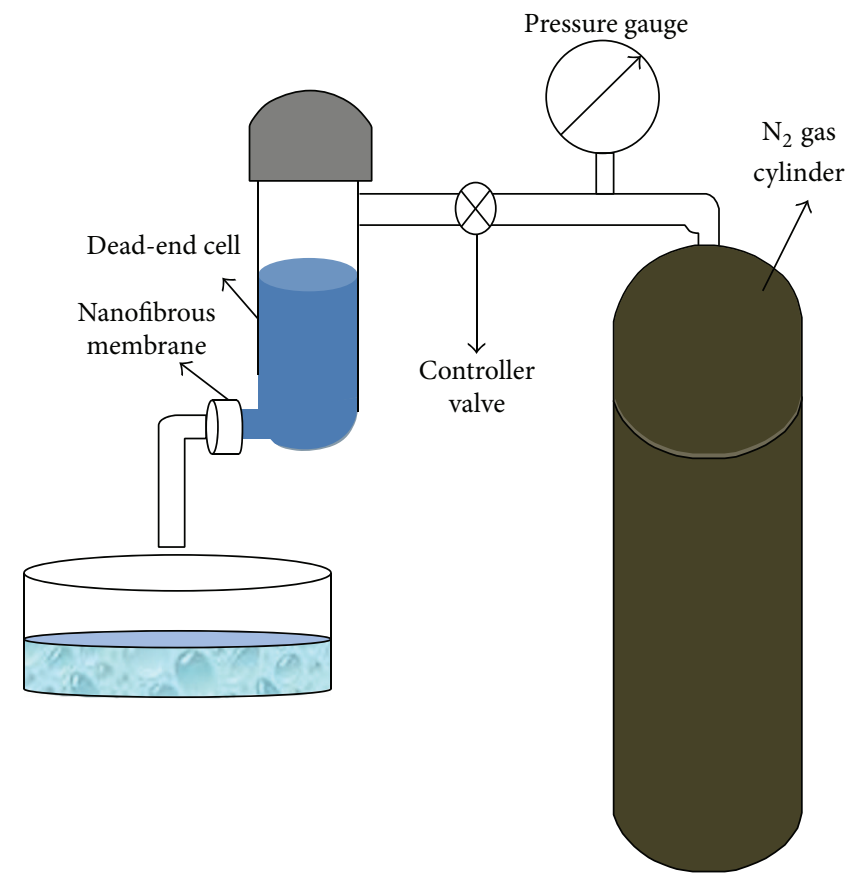

FIGURE 2: Schematic diagram of dead-end adsorption cell.

to $\mathrm{O}-\mathrm{H}$ and amine $\mathrm{N}-\mathrm{H}$ stretching of chitosan is obvious. In addition to the peak at $1,586 \mathrm{~cm}^{-1}$, assigned to amide II, there were also peaks at 1,650 characteristics of chitosan, which have been recognized as amide I bands. A peak around $1,016 \mathrm{~cm}^{-1}$ is corresponding to $\mathrm{C}-\mathrm{O}$ bending, typical of saccharide structure [22]. The spectrum (b) shows the characteristic bands of polyamide- 6 at $3430 \mathrm{~cm}^{-1}$ (H-bonded N$\mathrm{H}$ stretch vibration), $1642 \mathrm{~cm}^{-1}$ (amide $\mathrm{I}, \mathrm{C}-\mathrm{O}$ stretch), and $1542 \mathrm{~cm}^{-1}$ (amide II, C-N stretch and CO-N-H bend). The peak of $1645 \mathrm{~cm}^{-1}$ (amide I) is observed for the polyamide6/chitosan (spectrum (c)) which is attributed to the amino groups of blend nanofibers [15].

It is usually assumed that fouling decreases with an increase in hydrophilicity of the polymeric material. In fact, a decrease in contact angle leads to increase in the flux ratio, which means decreased fouling [23]. Therefore, evaluating the membrane characteristics was followed by contact angle measurements. Figure 5 shows the contact angle values of 

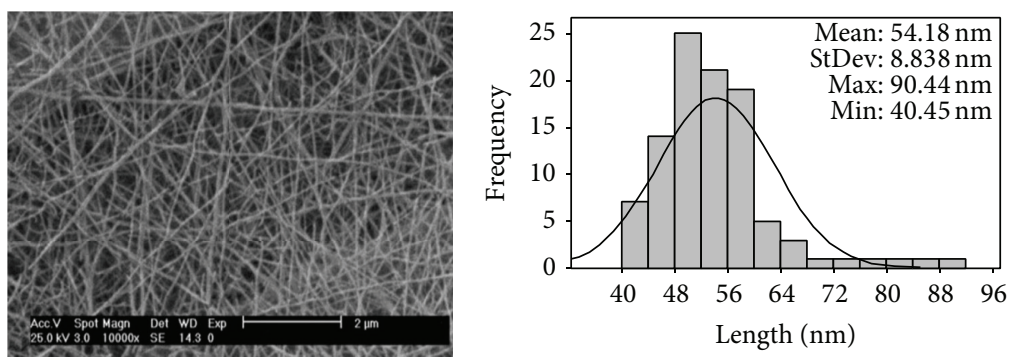

(a)
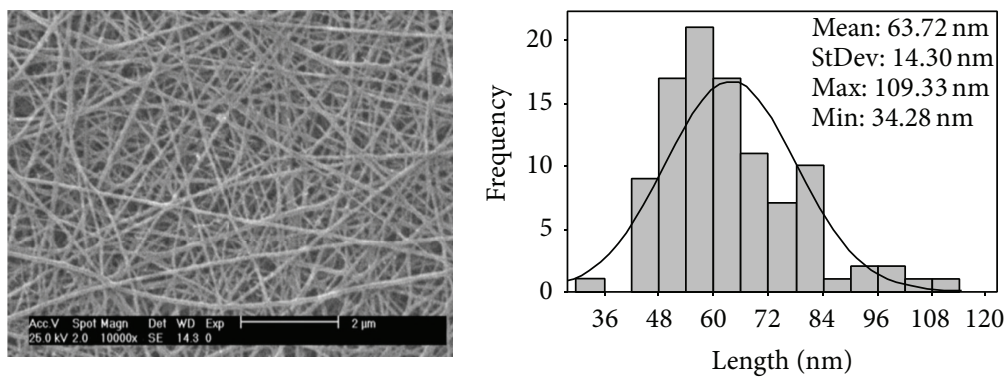

(b)
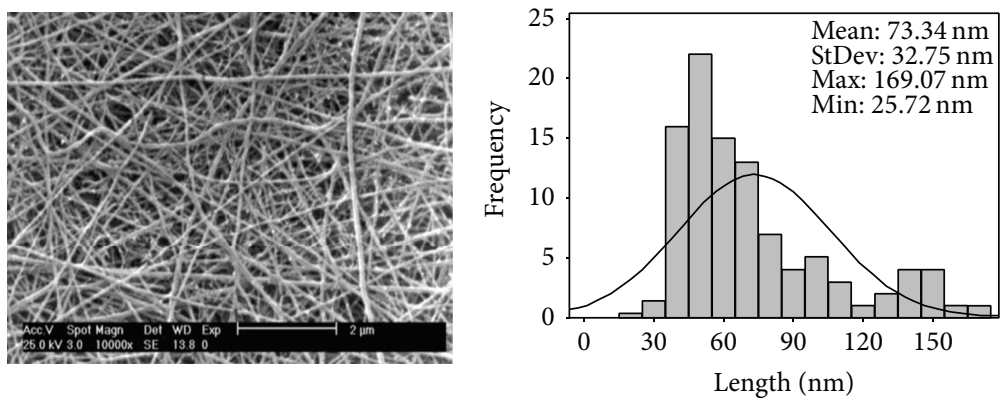

(c)
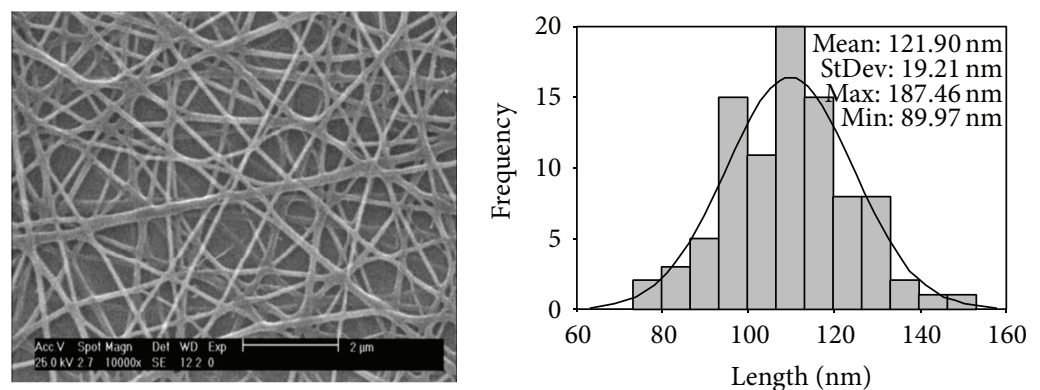

(d)
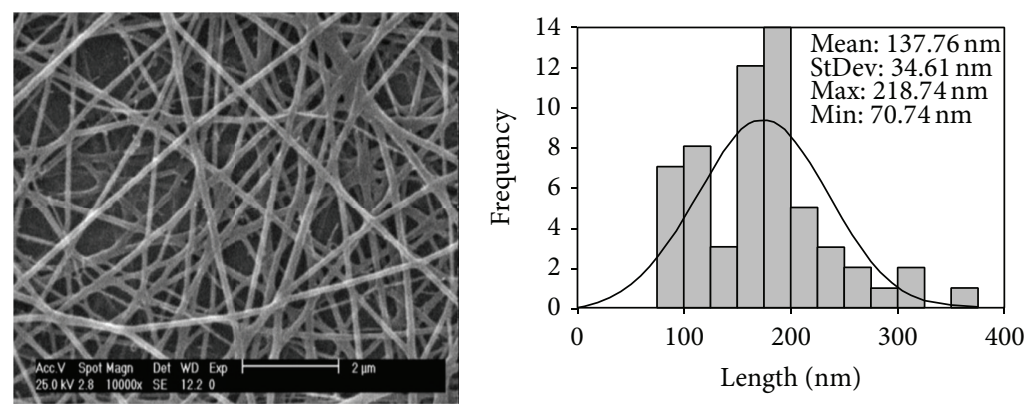

(e)

FIGURE 3: SEM images and diameter distribution of polyamide-6/chitosan nanofibers with different ratios: (a) 100/0, (b) 90/10, (c) 80/20, (d) $70 / 30$, and (e) 60/40. 


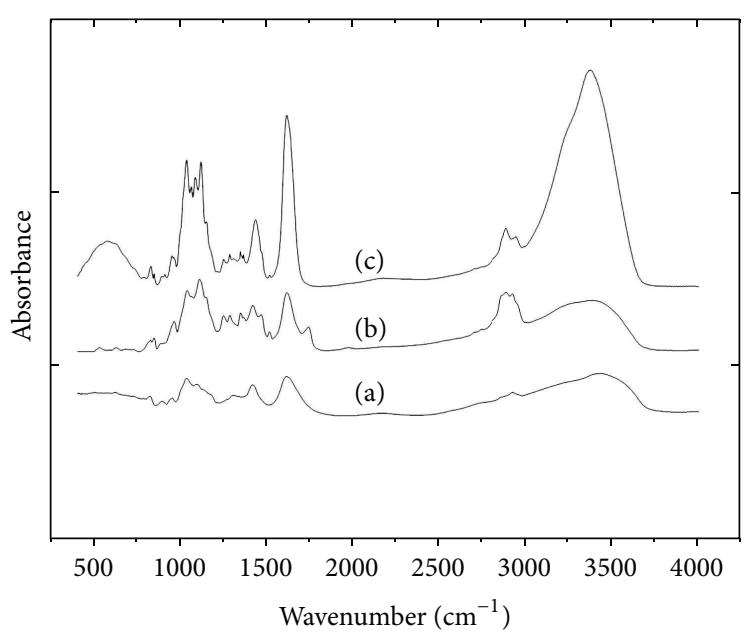

FIGURE 4: FT-IR spectra of (a) raw chitosan, (b) pure polyamide-6, and (c) electrospun nanofibers of polyamide-6/chitosan at $80 / 20$ weight ratio.

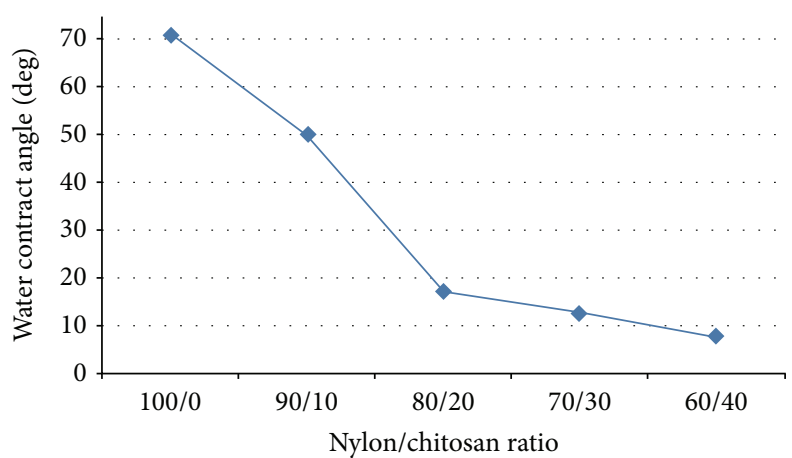

FIGURE 5: Water contact angle variations of various polyamide-6/chitosan electrospun nanofibrous membranes.

droplet with nanofibrous membranes after 4th second contact. Water contact angle for pure polyamide (PA) nanofiber is 71.2 while the polyamide-6/chitosan at weight ratio of $60 / 40$ shows WCA of 7.8 . The results indicated a significant improvement in hydrophilicity of membrane which is increasing by increasing the chitosan content. This can be attributed to the presence of a large number of functional groups (acetamide, primary amino, and/or hydroxyl groups) in chitosan interstructure. Similar outcomes are consistent with the work reported by Zhang et al. [11].

3.2. Model Development and Statistical Analysis. RSM is a combination of mathematical and statistical techniques used for modeling and optimizing of the processes. It is used to evaluate the relative significance of several affecting parameters even in the presence of complex interactions. CCD is one of the effective RSM designs that provides reasonable amount of information for testing the goodness of fit and does not require unusually large number of design points [24]. The results of the statistical analysis for removal efficiency of the direct (Solophenyl Red 3BL) and acidic (Polar Yellow GN) dyes according to analysis of variance (ANOVA) are brought in Table 3.

Model adequacy was tested according to the analysis of variance (ANOVA). As shown in Table 4, the significant
$P$ value of model and insignificant $P$ value of lack-of-fit indicated that the models are considered to be statistically significant for the present study. This means that regression models provide an excellent explanation of the relationship between observed and predicted values.

Values of probability $>F$ less than 0.05 indicated that the model terms were significant. In the case of Polar Yellow GN, $A, B, C, D, A D, B D, C D, A^{2}, B^{2}, C^{2}$, and $D^{2}$ were all significant model terms and $\mathrm{AB}, \mathrm{AC}$, and $\mathrm{BC}$ were insignificant to the response. For Solophenyl Red 3BL removal, A, B, C, D, AD, and $\mathrm{B}^{2}$ were significant model terms whereas $\mathrm{AB}, \mathrm{AC}, \mathrm{BC}$, $\mathrm{BD}, \mathrm{CD}, \mathrm{A}^{2}, \mathrm{C}^{2}$, and $\mathrm{D}^{2}$ were insignificant to the response.

The quadratic regression model for the removal efficiency of Polar Yellow GN $\left(Y_{1}\right)$ and Solophenyl Red 3BL $\left(Y_{2}\right)$ in terms of coded parameters is given by (4) and (5), respectively:

$$
\begin{aligned}
\text { (\%) } Y_{1}= & 66.00-10.25 \times \mathrm{A}+2.50 \times \mathrm{B}+6.08 \times \mathrm{C} \\
& +1.08 \times \mathrm{D}-2.25 \times \mathrm{AD}-2.12 \times \mathrm{BD} \\
& -1.37 \times \mathrm{CD}+3.06 \times \mathrm{A}^{2}+1.06 \times \mathrm{B}^{2} \\
& +2.69 \times \mathrm{C}^{2}+3.19 \times \mathrm{D}^{2} \\
\text { (\%) } Y_{2}= & 71.17-9.33 \times \mathrm{A}-0.17 \times \mathrm{B} \\
& +4.83 \times \mathrm{C}+3.25 \times \mathrm{D}-5.25 \times \mathrm{AD} \\
& +2.33 \times \mathrm{B}^{2} .
\end{aligned}
$$


TABLE 3: Full factorial central composite design for removal of Solophenyl Red 3BL and Polar Yellow GN.

\begin{tabular}{|c|c|c|c|c|c|c|c|c|}
\hline \multirow{2}{*}{$\begin{array}{l}\text { Run } \\
\text { no. }\end{array}$} & \multirow{2}{*}{$\begin{array}{c}\text { Solution } \\
\mathrm{PH}(\mathrm{A})\end{array}$} & \multirow{2}{*}{$\begin{array}{c}\text { Initial dye } \\
\text { concentration (B) }\end{array}$} & \multirow{2}{*}{$\begin{array}{l}\text { Electrospinning } \\
\text { time }(\mathrm{C})\end{array}$} & \multirow{2}{*}{$\begin{array}{l}\text { Chitosan } \\
\text { ratio (D) }\end{array}$} & \multicolumn{4}{|c|}{ (\%) removal (Solophenyl Red 3BL) (\%) removal (Polar Yellow GN) } \\
\hline & & & & & Exp. & Predicted & Exp. & Predicted \\
\hline 1 & 5 & 50 & 2 & 10 & 68 & 69.67 & 72 & 70.83 \\
\hline 2 & 9 & 50 & 2 & 10 & 61 & 61.5 & 56 & 54.83 \\
\hline 3 & 5 & 100 & 2 & 10 & 71 & 69.33 & 79 & 80.08 \\
\hline 4 & 9 & 100 & 2 & 10 & 64 & 61.16 & 61 & 64.08 \\
\hline 5 & 5 & 50 & 4 & 10 & 75 & 79.33 & 83 & 85.75 \\
\hline 6 & 9 & 50 & 4 & 10 & 68 & 71.17 & 69 & 69.75 \\
\hline 7 & 5 & 100 & 4 & 10 & 76 & 78.99 & 97 & 95 \\
\hline 8 & 9 & 100 & 4 & 10 & 67 & 70.83 & 78 & 79 \\
\hline 9 & 5 & 50 & 2 & 30 & 83 & 86.67 & 84 & 84.5 \\
\hline 10 & 9 & 50 & 2 & 30 & 58 & 57.49 & 61 & 59.5 \\
\hline 11 & 5 & 100 & 2 & 30 & 88 & 86.33 & 86 & 85.25 \\
\hline 12 & 9 & 100 & 2 & 30 & 59 & 57.17 & 62 & 60.25 \\
\hline 13 & 5 & 50 & 4 & 30 & 97 & 96.33 & 95 & 93.91 \\
\hline 14 & 9 & 50 & 4 & 30 & 69 & 67.17 & 71 & 68.92 \\
\hline 15 & 5 & 100 & 4 & 30 & 98 & 95.99 & 98 & 94.67 \\
\hline 16 & 9 & 100 & 4 & 30 & 66 & 66.83 & 66 & 69.67 \\
\hline 17 & 3 & 75 & 3 & 20 & 92 & 89.83 & 97 & 98.75 \\
\hline 18 & 11 & 75 & 3 & 20 & 52 & 52.5 & 59 & 57.75 \\
\hline 19 & 7 & 25 & 3 & 20 & 85 & 80.83 & 64 & 65.25 \\
\hline 20 & 7 & 125 & 3 & 20 & 78 & 80.17 & 76 & 75.25 \\
\hline 21 & 7 & 75 & 1 & 20 & 57 & 61.5 & 64 & 64.58 \\
\hline 22 & 7 & 75 & 5 & 20 & 83 & 80.83 & 89 & 88.92 \\
\hline 23 & 7 & 75 & 3 & 0 & 74 & 64.67 & 79 & 76.58 \\
\hline 24 & 7 & 75 & 3 & 40 & 79 & 77.67 & 78 & 80.92 \\
\hline 25 & 7 & 75 & 3 & 20 & 72 & 77.67 & 64 & 66 \\
\hline 26 & 7 & 75 & 3 & 20 & 69 & 77.67 & 68 & 66 \\
\hline 27 & 7 & 75 & 3 & 20 & 73 & 77.67 & 66 & 66 \\
\hline 28 & 7 & 75 & 3 & 20 & 71 & 77.67 & 65 & 66 \\
\hline 29 & 7 & 75 & 3 & 20 & 70 & 77.67 & 67 & 66 \\
\hline 30 & 7 & 75 & 3 & 20 & 68 & 77.67 & 66 & 66 \\
\hline
\end{tabular}

TABLE 4: Analysis of variance for two acid and direct dyes.

\begin{tabular}{lcccc}
\hline \multirow{2}{*}{ Source } & \multicolumn{2}{c}{ Polar Yellow GN } & \multicolumn{2}{c}{ Solophenyl Red 3BL } \\
& $F$-value & $P$ value $(P>F)$ & $F$-value & $P$ value $(P>F)$ \\
\hline Model & 65.05 & $<0.0001$ & 24.17 & $<0.0001$ \\
$\mathrm{~A}$ & 525.92 & $<0.0001$ & 196.51 & $<0.0001$ \\
$\mathrm{~B}$ & 31.28 & $<0.0001$ & 0.06 & 0.8057 \\
$\mathrm{C}$ & 185.25 & $<0.0001$ & 52.70 & $<0.0001$ \\
$\mathrm{D}$ & 5.87 & 0.0285 & 23.83 & 0.0002 \\
$\mathrm{AB}$ & 3.34 & 0.0877 & 0.59 & 0.4553 \\
$\mathrm{AC}$ & 0.83 & 0.3755 & 0.37 & 0.5489 \\
$\mathrm{AD}$ & 16.89 & 0.0009 & 41.45 & $<0.0001$ \\
$\mathrm{BC}$ & 0.47 & 0.5038 & 1.15 & 0.3002 \\
$\mathrm{BD}$ & 15.07 & 0.0015 & 0.02 & 0.8802 \\
$\mathrm{CD}$ & 6.31 & 0.0239 & 2.35 & 0.1461 \\
$\mathrm{~A}^{2}$ & 53.65 & $<0.0001$ & 0.05 & 0.9475 \\
$\mathrm{~B}^{2}$ & 6.46 & 0.0226 & 15.06 & 0.0015 \\
$\mathrm{C}^{2}$ & 41.32 & $<0.0001$ & 0.54 & 0.4731 \\
$\mathrm{D}^{2}$ & 58.12 & $<0.0001$ & 3.51 & 0.0807 \\
Lack of fit & 3.09 & 0.1120 & 4.06 & 0.0677 \\
\hline
\end{tabular}

The value of regression coefficient $\left(R^{2}\right)$ for each response was evaluated. The $R^{2}$ value for removing Polar Yellow GN and Solophenyl Red 3BL by using polyamidee-6/chitosan electrospun nanofibrous membrane was 0.9788 and 0.9320 , respectively. This indicates that the correlations are best suited in predicting the values for the dye removal and the predicted values are found to be closer to the experimental results.

3.3. Filtration Studies. As discussed previously, the CCD was used with two solution parameters and two membrane parameters to investigate their effects on the filtration process. The $2 \mathrm{D}$ contour plots and $3 \mathrm{D}$ response surfaces as a graphical representation of the regression equation were investigated to identify the parameters effects.

3.3.1. Effects of Solution Parameters. The $\mathrm{pH}$ of the dye solution plays very important role in the adsorption process, influencing not only parameters such as the surface charge of the membrane, the degree of ionization of the materials present in the solution, and the dissociation of functional 


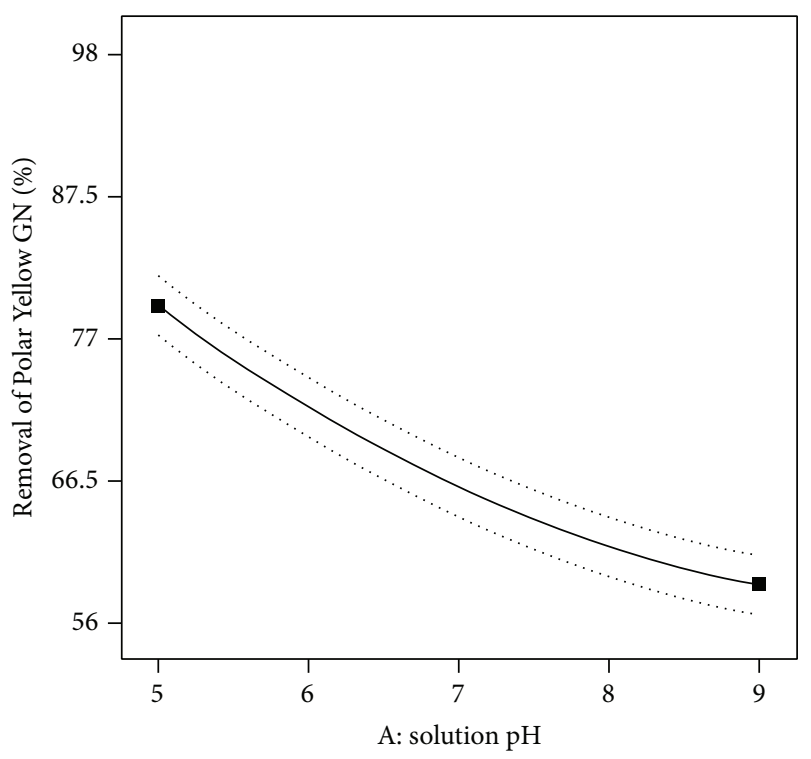

(a)

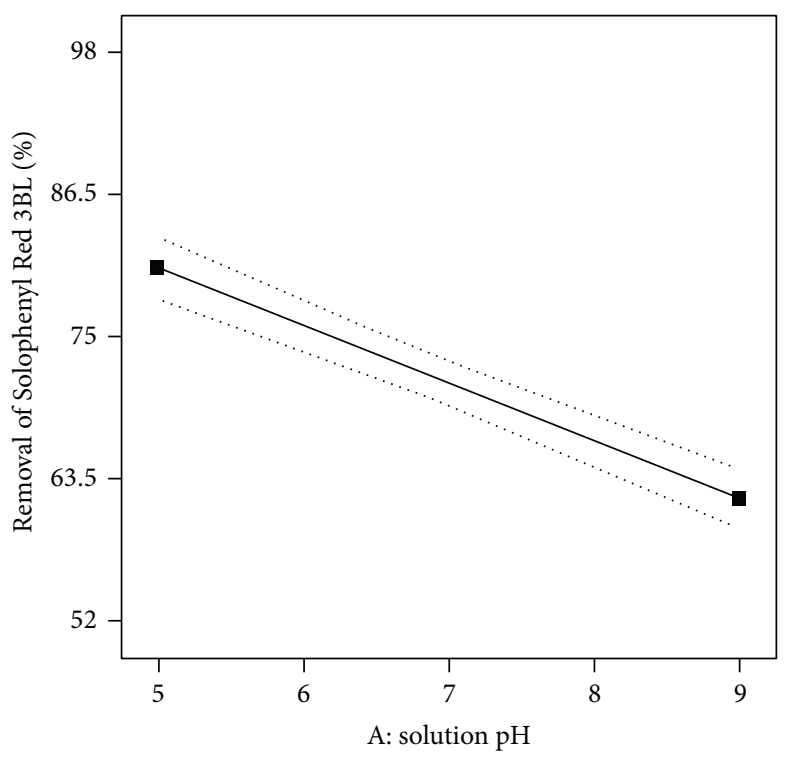

(b)

FIGURE 6: Effect of $\mathrm{pH}$ on the removal of acidic (Polar Yellow GN) and direct dyes (Solophenyl Red 3BL).

groups on the active sites of the membrane but also the solution dye chemistry and species distribution of the dyestuff $[25,26]$. The effects of solution $\mathrm{pH}$ on the removal of Polar Yellow GN as an acid dye and Solophenyl Red 3BL as a direct dye onto polyamide-6/chitosan nanofibrous membrane are shown in Figure 6.

From the figures it can be seen that there is a direct connection between solution $\mathrm{pH}$ and dye removal. Since over $90 \%$ of the chitosan amino groups are protonated at acidic $\mathrm{pH}$ [27], maximum removal efficiency of the dyes was observed in the lowest $\mathrm{pH}$ levels. Since at lower $\mathrm{pH}$ more protons will be available to protonate amine groups of chitosan molecules $[28,29]$, then strong electrostatic interaction between the membrane surface and the dye anions results in an increase of dye removal, and increasing the $\mathrm{pH}$ causes decreasing the removal efficiency. Moreover, looking at (4) and (5) reveals that $\mathrm{pH}$ is the most important parameter in filtration process.

Figure 7 shows the combined effect of $\mathrm{pH}$ and chitosan ratio on the dye removal. It was inferred that for both of the dyes at a given chitosan ratio, decreasing of the $\mathrm{pH}$ results in increasing the removal efficiency. The maximum removal efficiency was observed at the lowest $\mathrm{pH}$ and the highest chitosan ratio. In other words, increasing the chitosan ratio and decreasing the $\mathrm{pH}$ at the same time will increase the amount of protonated groups of chitosan and therefore removal efficiency.

At the constant amount of adsorbent as reported in the literature in the static system [30,31], with an increase in the initial concentration of dye the amount of the dye adsorbed onto chitosan would be increased. That is, while our study on dynamic systems showed that increasing the initial concentration was not affected solitarily (see (1) and (2)), Figure 8, for Polar Yellow GN, demonstrates that, with increasing of initial concentration, the removal efficiency increases with the chitosan ratio. In fact, increasing the adsorption sites of chitosan enhanced the effect of increasing the dye concentration and improved applicability of the membrane to remove the dye. In other words, increasing the initial dye concentration at higher chitosan content has led to improved removal of efficiency of acidic dye.

3.3.2. Effect of Membrane Parameters. Performance behavior of the membrane affected physical characteristics such as thickness [32]. Effect of the membrane thickness on the removal of acidic and direct dyes was investigated through changing the electrospinning time. Generally increasing the thickness leads to increasing removal efficiency of membrane $[7,33]$. It can be seen from Figure 9 that the relationship between the electrospinning time and the direct dye removal is linear. Direct dye has a natural tendency to undergo aggregation [34]. This tendency can be a possible explanation for its more removal efficiency.

Increasing the chitosan ratio in the blended solution results in an increase in hydrophilicity properties (Section 3.1) and number of active groups of nanofibrous membrane in which generally both of them directly affect excellent adsorption behavior of polysaccharides structures [10,35]. Effect of chitosan ratio on dye removal efficiency has been shown in Figure 10. However increasing the chitosan ratio of the blended solution has a slight effect on the dye removal efficiency; it is more pronounced for Solophenyl Red 3BL which can be attributed to presence of more sulfonyl groups in its chemical structure as shown in Table 2.

3.4. Response Optimization. One of the objectives of the experimental design was to optimize the process conditions for maximizing the removal efficiency of Solophenyl Red 3BL and Polar Yellow GN. Desirability function $(D)$ was defined in ranges from zero outside of the limits to one at the goal. This set gave the highest $D$ at 0.964 and 0.929 for Solophenyl 
TABLE 5: Experimental and predicted values of dye removal for optimized condition obtained from model.

\begin{tabular}{lcccccc}
\hline Dye & Solution $\mathrm{pH}$ & Initial concentration & Electrospinning time & Chitosan ratio & Predict & Experimental dye removal \\
\hline Solophenyl Red 3BL & 5 & 50 & 4 & 30 & 96.33 & 98.1 \\
Polar yellow GN & 5 & 100 & 4 & 10 & 94.827 & 93.2 \\
\hline
\end{tabular}

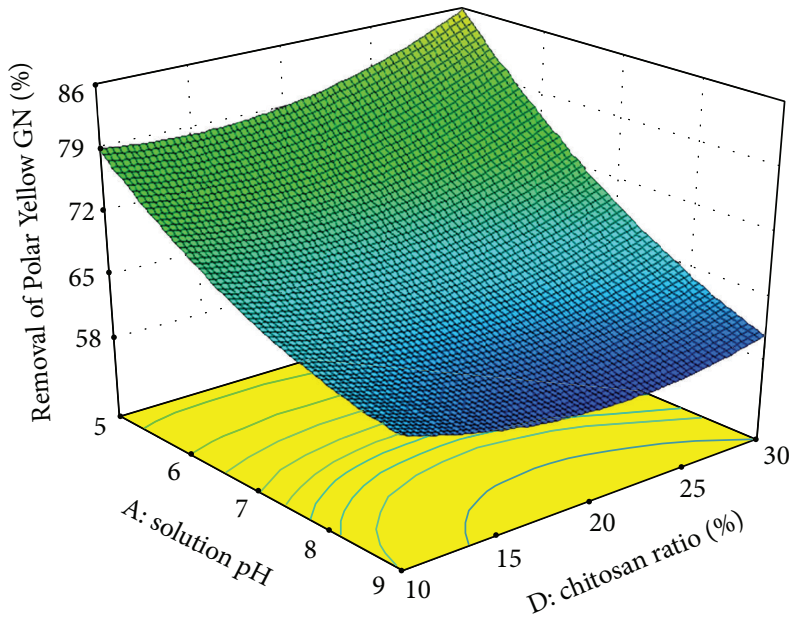

(a)

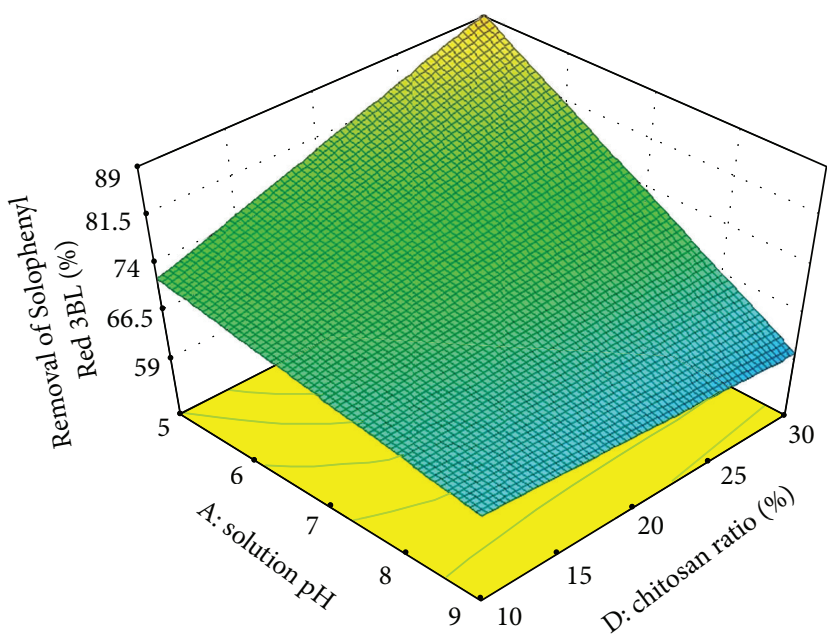

(b)

FIGURE 7: 3D surface plots of the dye removal for the chitosan ration and solution $\mathrm{pH}$.

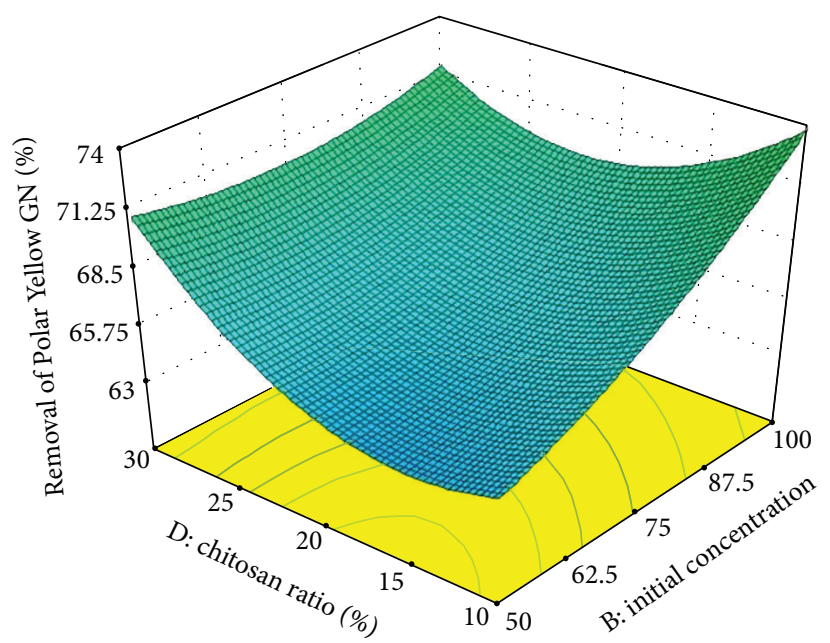

FIGURE 8: 3D surface plot of the dye removal for the chitosan ration and initial dye concentration.

Red 3BL and Polar Yellow GN, respectively. In this case the optimized parameters to obtain maximum dye removal efficiency are presented in Table 5.

It can be observed from Table 5 that the experimental values are in good agreement with the values predicted from the models. There were relatively small errors between the predicted and the actual values, which was only 1.804 and $1.746 \%$, for Solophenyl Red 3BL and Polar Yellow GN, respectively.

\section{Conclusion}

Removal of acidic and direct dyes using polyamide-6/chitosan nanofibrous filter media has been investigated with response surface methodology based on CCD. The ANOVA results revealed that the proposed regression model based on CCD was in agreement with the experimental data. The models were derived based on the results and the response surface plots were obtained accordingly. For both dyes the effect 


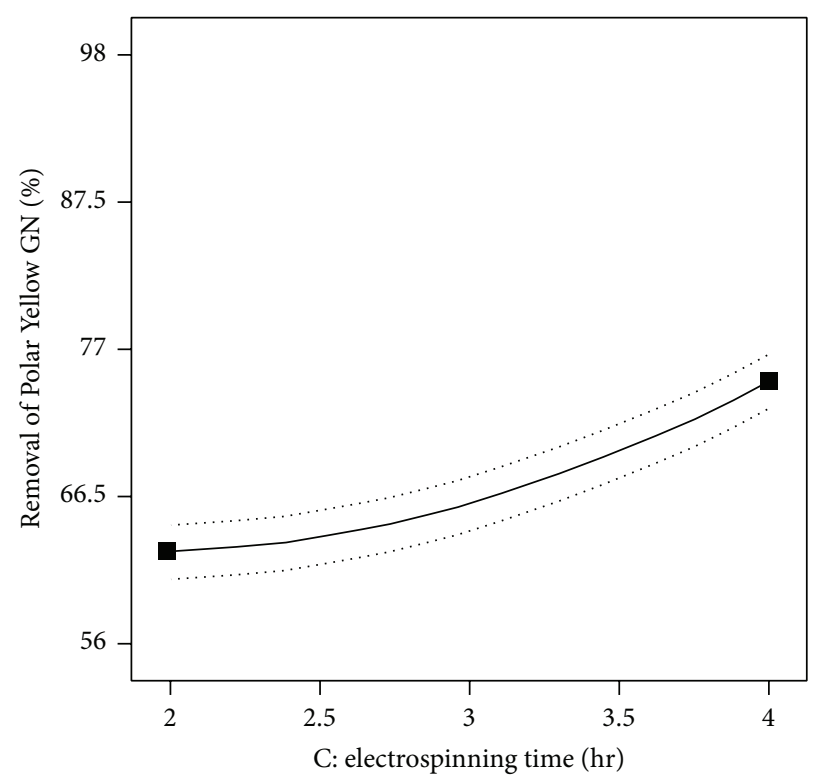

(a)

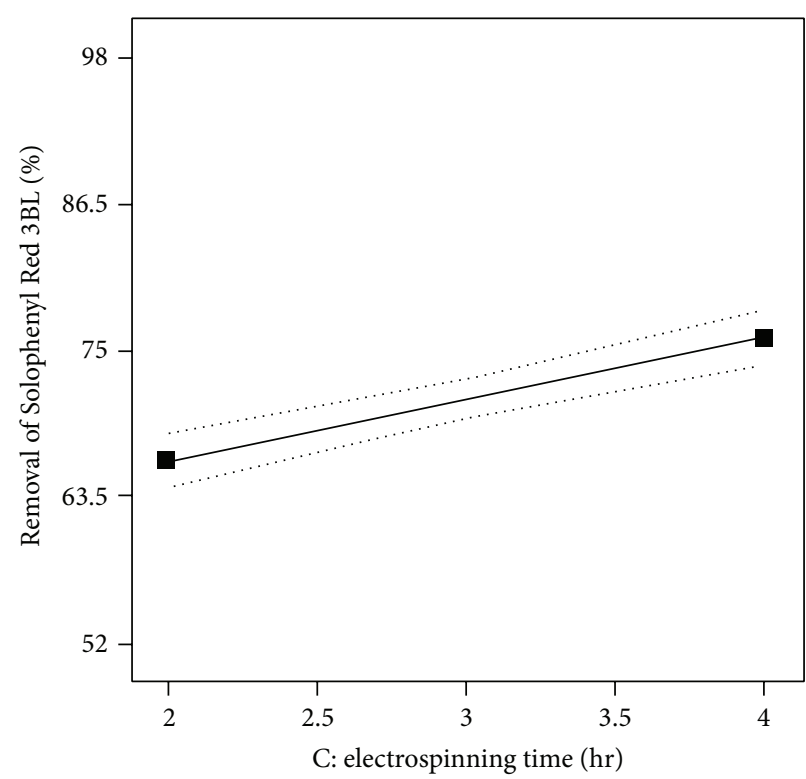

(b)

FIGURE 9: Effect of electrospinning time on the removal of acidic and direct dyes.

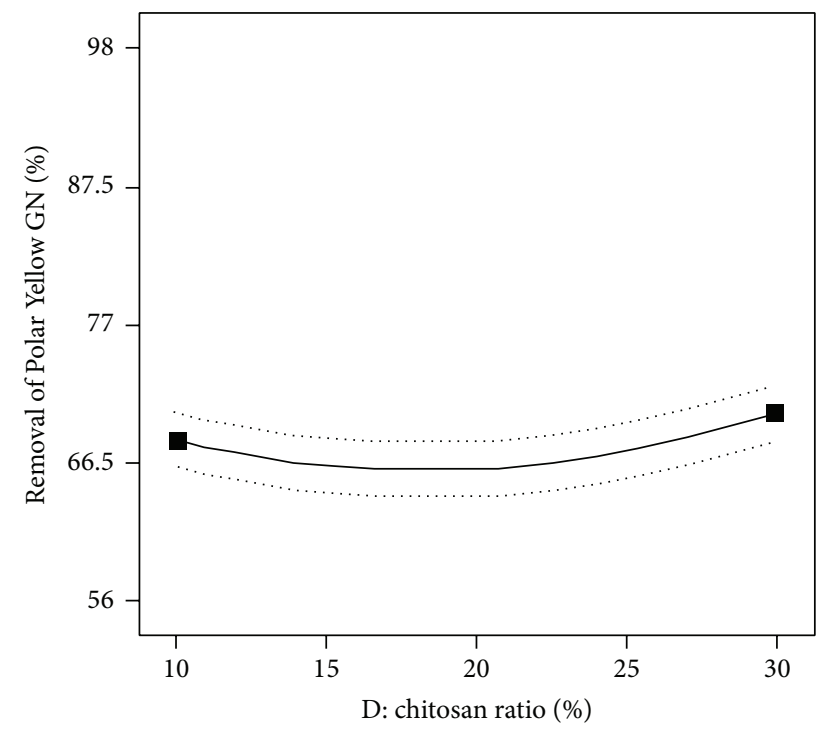

(a)

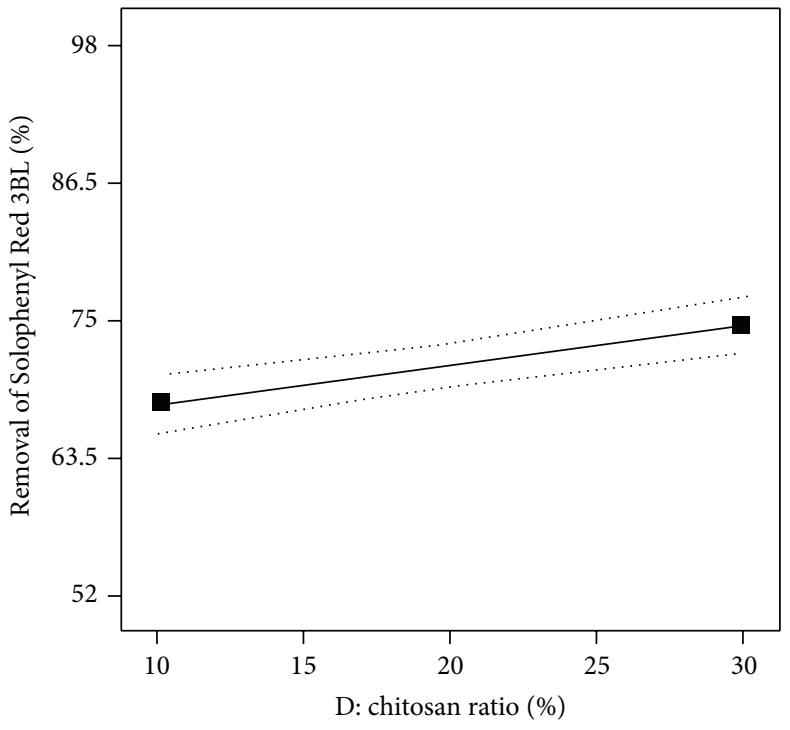

(b)

FIGURE 10: Effect of chitosan ratio on the removal of acidic and direct dyes.

of increasing the chitosan ratio on dye removal efficiency was positive, while the effects of increasing the solution $\mathrm{pH}$ value and initial concentration were negative, in which the maximum removal efficiency was observed at the lowest $\mathrm{pH}$ and the highest chitosan ratio. Moreover, for Polar Yellow $\mathrm{GN}$ the interaction between initial dye concentration and $\mathrm{pH}$ value was significant in which increasing the initial dye concentration at higher chitosan content led to improve removal efficiency of acidic dyes. The dye removal efficiency increased with the increase of the electrospinning time that was more significant for direct dye. In addition, the effect of chitosan ratio was of lower importance for acidic dye than that for direct dye in which there was more or less linear relationship between chitosan ratio and dye removal efficiency. The best filtration condition under CCD was found at $\mathrm{pH}=5$, initial dye concentration $=100 \mathrm{mg} / \mathrm{L}$, electrospinning time $=4 \mathrm{hr}$, and chitosan ratio $=10 \%$ with $94.827 \%$ dye removal for Polar Yellow GN. That is, while these values were obtained: 5, $50 \mathrm{mg} / \mathrm{L}, 4 \mathrm{hr}$, and 30\% for Solophenyl Red 3BL which had $96.33 \%$ dye removal. Based on these results, it can be concluded that polyamide-6/chitosan nanofibrous filter media are promising for dye removal from wastewater. 


\section{Conflict of Interests}

The authors declare that there is no conflict of interests regarding the publication of this paper.

\section{Acknowledgment}

Authors acknowledge the Deputy of Research Affairs of Amirkabir University of Technology (AUT) for funding support of the project.

\section{References}

[1] E. Forgacs, T. Cserháti, and G. Oros, "Removal of synthetic dyes from wastewaters: a review," Environment International, vol. 30, no. 7, pp. 953-971, 2004.

[2] Y. Xu, R. E. Lebrun, P.-J. Gallo, and P. Blond, "Treatment of textile dye plant effluent by nanofiltration membrane," Separation Science and Technology, vol. 34, no. 13, pp. 2501-2519, 1999.

[3] M. Amini, M. Arami, N. M. Mahmoodi, and A. Akbari, "Dye removal from colored textile wastewater using acrylic grafted nanomembrane," Desalination, vol. 267, no. 1, pp. 107-113, 2011.

[4] C.-E. Nielson, "Recycling of wastewaters from textile dyeing using crossflow membrane filtration," Filtration and Separation, vol. 31, no. 6, pp. 593-595, 1994.

[5] G. Singh, D. Rana, T. Matsuura, S. Ramakrishna, R. M. Narbaitz, and S. Tabe, "Removal of disinfection byproducts from water by carbonized electrospun nanofibrous membranes," Separation and Purification Technology, vol. 74, no. 2, pp. 202-212, 2010.

[6] K. Yoon, B. S. Hsiao, and B. Chu, "Formation of functional polyethersulfone electrospun membrane for water purification by mixed solvent and oxidation processes," Polymer, vol. 50, no. 13, pp. 2893-2899, 2009.

[7] A. M. Bazargan, M. Keyanpour-rad, F. A. Hesari, and M. E. Ganji, "A study on the microfiltration behavior of self-supporting electrospun nanofibrous membrane in water using an optical particle counter," Desalination, vol. 265, no. 1-3, pp. 148152, 2011.

[8] M. Teng, F. Li, B. Zhang, and A. A. Taha, "Electrospun cyclodextrin-functionalized mesoporous polyvinyl alcohol $/ \mathrm{SiO}_{2}$ nanofiber membranes as a highly efficient adsorbent for indigo carmine dye," Colloids and Surfaces A, vol. 385, no. 1-3, pp. 229234, 2011.

[9] M. Min, L. Shen, G. Hong et al., "Micro-nano structure poly (Ether Sulfones)/poly (Ethyleneimine) nanofibrous affinity membranes for adsorption of anionic dyes and heavy metal ions in aqueous solution," Chemical Engineering Journal, vol. 197, pp. 88-100, 2012.

[10] G. Crini and P.-M. Badot, "Application of chitosan, a natural aminopolysaccharide, for dye removal from aqueous solutions by adsorption processes using batch studies: a review of recent literature," Progress in Polymer Science, vol. 33, no. 4, pp. 399447, 2008.

[11] H. Zhang, S. Li, C. J. Branford White, X. Ning, H. Nie, and L. Zhu, "Studies on electrospun nylon-6/chitosan complex nanofiber interactions," Electrochimica Acta, vol. 54, no. 24, pp. 5739$5745,2009$.

[12] K. Kurita, "Chitin and chitosan: functional biopolymers from marine crustaceans," Marine Biotechnology, vol. 8, no. 3, pp. 203-226, 2006.
[13] E. Guibal, "Interactions of metal ions with chitosan-based sorbents: a review," Separation and Purification Technology, vol. 38, no. 1, pp. 43-74, 2004.

[14] H. Honarkar and M. Barikani, "Applications of biopolymers I: chitosan," Monatshefte fur Chemie, vol. 140, no. 12, pp. 14031420, 2009.

[15] R. Nirmala, R. Navamathavan, H.-S. Kang, M. H. El-Newehy, and H. Y. Kim, "Preparation of polyamide-6/chitosan composite nanofibers by a single solvent system via electrospinning for biomedical applications," Colloids and Surfaces B, vol. 83, no. 1, pp. 173-178, 2011.

[16] R. Nirmala, R. Navamathavan, M. H. El-Newehy, and H. Y. Kim, "Preparation and electrical characterization of polyamide6/chitosan composite nanofibers via electrospinning," Materials Letters, vol. 65, no. 3, pp. 493-496, 2011.

[17] H. Zhang, C. Wu, Y. Zhang et al., "Elaboration, characterization and study of a novel affinity membrane made from electrospun hybrid chitosan/nylon-6 nanofibers for papain purification," Journal of Materials Science, vol. 45, no. 9, pp. 2296-2304, 2010.

[18] J. S. Stephens, D. B. Chase, and J. F. Rabolt, "Effect of the electrospinning process on polymer crystallization chain conformation in nylon-6 and nylon-12," Macromolecules, vol. 37, no. 3, pp. 877-881, 2004

[19] M. A. Bezerra, R. E. Santelli, E. P. Oliveira, L. S. Villar, and L. A. Escaleira, "Response surface methodology (RSM) as a tool for optimization in analytical chemistry," Talanta, vol. 76, no. 5, pp. 965-977, 2008.

[20] A. R. Khataee, M. B. Kasiri, and L. Alidokht, "Application of response surface methodology in the optimization of photocatalytic removal of environmental pollutants using nanocatalysts," Environmental Technology, vol. 32, no. 15, pp. 1669-1684, 2011.

[21] J. M. Deitzel, J. Kleinmeyer, D. Harris, and N. C. Beck Tan, "The effect of processing variables on the morphology of electrospun nanofibers and textiles," Polymer, vol. 42, no. 1, pp. 261-272, 2001.

[22] E. Campos, P. Coimbra, and M. H. Gil, "An improved method for preparing glutaraldehyde cross-linked chitosan-poly (Vinyl Alcohol) microparticles," Polymer Bulletin, 2012.

[23] D. Rana and T. Matsuura, "Surface modifications for antifouling membranes," Chemical Reviews, vol. 110, no. 4, pp. 2448-2471, 2010.

[24] S. Sharma, A. Malik, and S. Satya, "Application of response surface methodology (RSM) for optimization of nutrient supplementation for Cr (VI) removal by Aspergillus lentulus AML05," Journal of Hazardous Materials, vol. 164, no. 2-3, pp. 1198-1204, 2009.

[25] G. Crini, "Recent developments in polysaccharide-based materials used as adsorbents in wastewater treatment," Progress in Polymer Science, vol. 30, no. 1, pp. 38-70, 2005.

[26] Y. Ku, P.-L. Lee, and W.-Y. Wang, "Removal of acidic dyestuffs in aqueous solution by nanofiltration," Journal of Membrane Science, vol. 250, no. 1-2, pp. 159-165, 2005.

[27] C. Gerente, V. K. C. Lee, P. Le Cloirec, and G. McKay, "Application of chitosan for the removal of metals from wastewaters by adsorption-mechanisms and models review," Critical Reviews in Environmental Science and Technology, vol. 37, no. 1, pp. 41127, 2007.

[28] H. Yoshida, A. Okamoto, and T. Kataoka, "Adsorption of acid dye on cross-linked chitosan fibers: equilibria," Chemical Engineering Science, vol. 48, no. 12, pp. 2267-2272, 1993. 
[29] M. N. V. Ravi Kumar, "A review of chitin and chitosan applications," Reactive and Functional Polymers, vol. 46, no. 1, pp. 1-27, 2000.

[30] R. D. Cho, Y.-Y. Park, and K.-Y. Kim, "Adsorption of toluidine blue O onto chitosan," Journal of Agricultural and Food Chemistry, vol. 38, no. 5, pp. 447-451, 1995.

[31] D. Knorr, "Dye binding properties of chitin and chitosan," Journal of Food Science, vol. 48, no. 1, pp. 36-37, 1983.

[32] A. Patanaik, V. Jacobs, and R. D. Anandjiwala, "Performance evaluation of electrospun nanofibrous membrane," Journal of Membrane Science, vol. 352, no. 1-2, pp. 136-142, 2010.

[33] K. Kim, C. Lee, I. W. Kim, and J. Kim, "Performance modification of a melt-blown filter medium via an additional nano-web layer prepared by electrospinning," Fibers and Polymers, vol. 10, no. 1, pp. 60-64, 2009.

[34] H. Klaus, Industrial Dyes, Wiley-Vch, 2007.

[35] F. Esther, T. Cserhati, and G. Oros, "Removal of synthetic dyes from wastewaters: a review," Environment International, vol. 30, no. 7, pp. 953-971, 2004. 

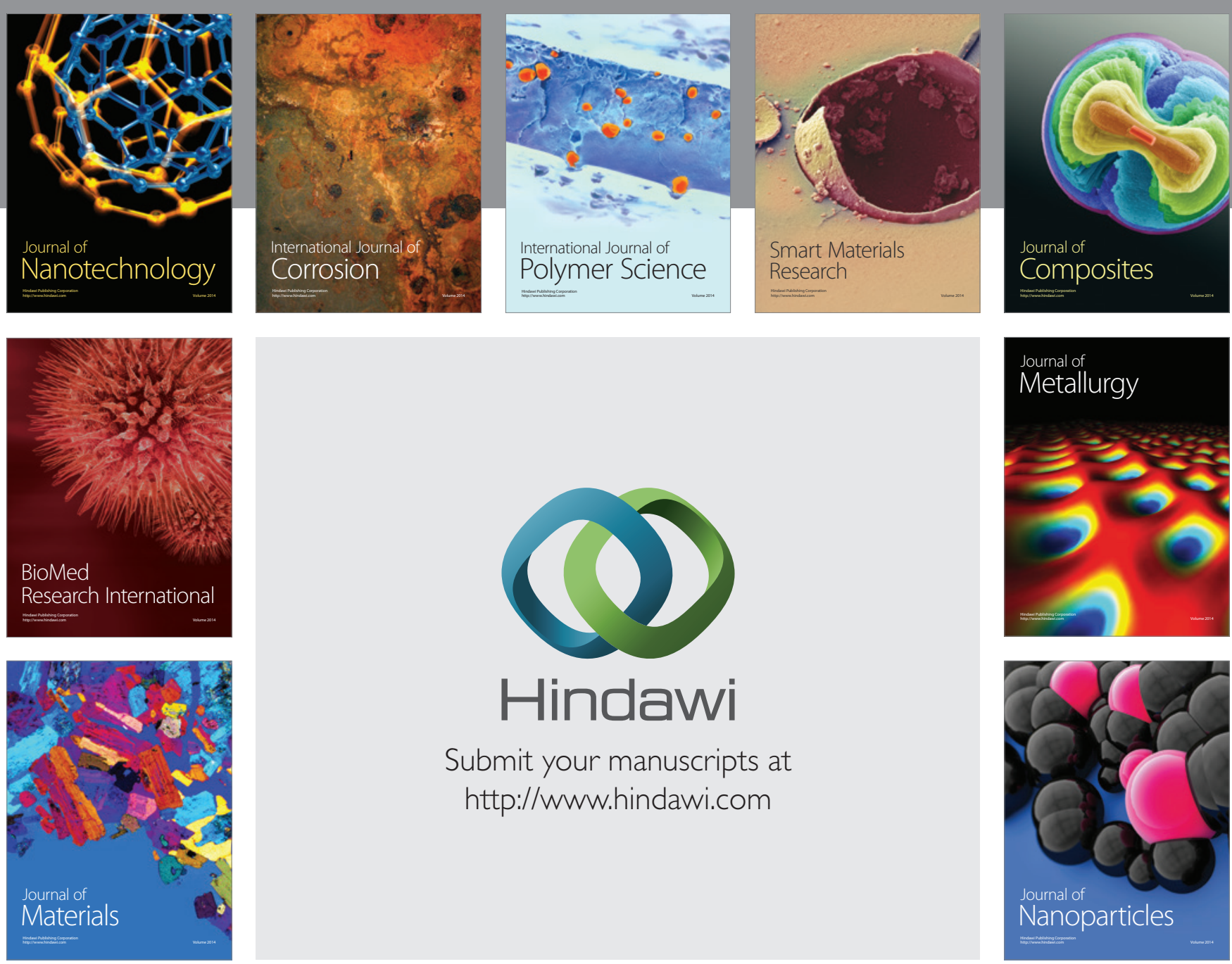

Submit your manuscripts at http://www.hindawi.com
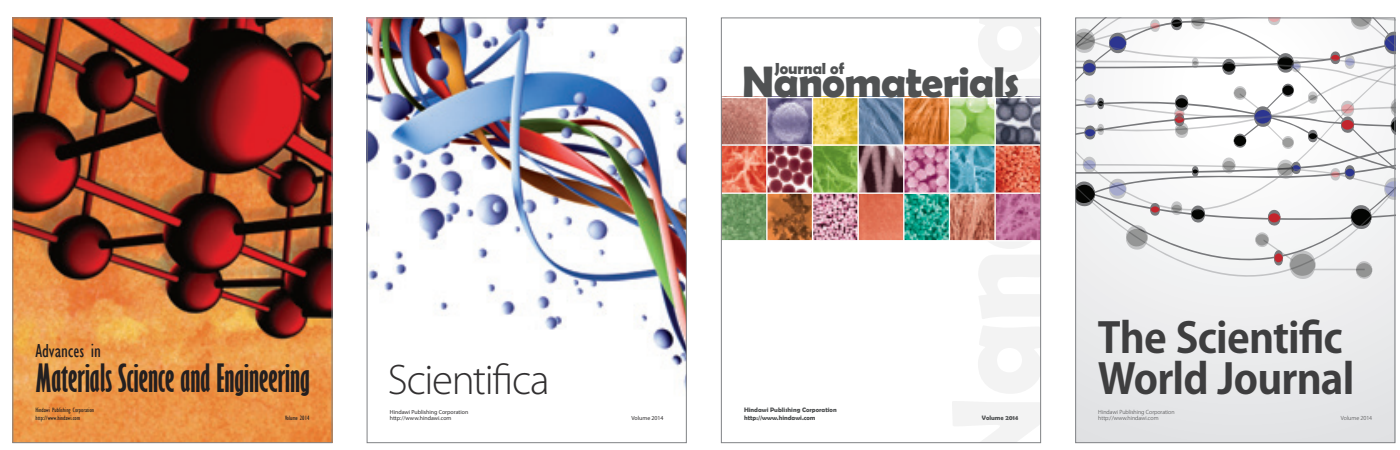

\section{The Scientific World Journal}
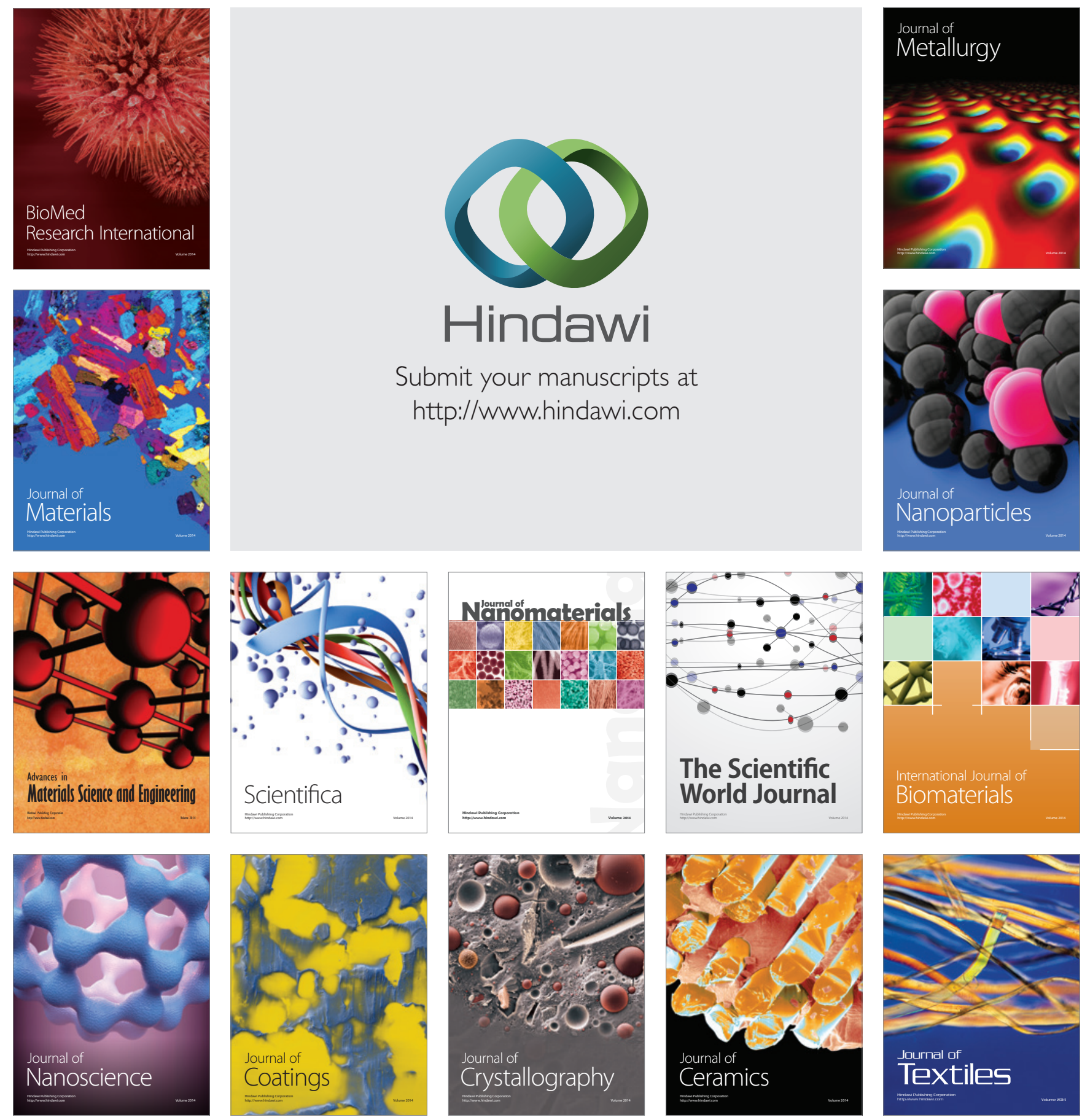